\title{
To mesh or not to mesh: a review of pelvic organ reconstructive surgery
}

\author{
This article was published in the following Dove Press journal: \\ International Journal of Women's Health \\ I April 2015 \\ Number of times this article has been viewed
}

\section{Patrick Dällenbach}

Department of Gynecology and Obstetrics, Division of Gynecology, Urogynecology Unit, Geneva University Hospitals, Geneva, Switzerland
Correspondence: Patrick Dällenbach Department of Gynecology and Obstetrics, Division of Gynecology, Urogynecology Unit, Geneva University Hospitals, 30 Boulevard de la Cluse, I21 I Genève 14, Switzerland

$\mathrm{Tel}+4 \mathrm{I} 223826816$

Fax +4I 223824424

Email patrick.dallenbach@hcuge.ch

\begin{abstract}
Pelvic organ prolapse (POP) is a major health issue with a lifetime risk of undergoing at least one surgical intervention estimated at close to $10 \%$. In the $1990 \mathrm{~s}$, the risk of reoperation after primary standard vaginal procedure was estimated to be as high as $30 \%$ to $50 \%$. In order to reduce the risk of relapse, gynecological surgeons started to use mesh implants in pelvic organ reconstructive surgery with the emergence of new complications. Recent studies have nevertheless shown that the risk of POP recurrence requiring reoperation is lower than previously estimated, being closer to $10 \%$ rather than $30 \%$. The development of mesh surgery actively promoted by the marketing industry - was tremendous during the past decade, and preceded any studies supporting its benefit for our patients. Randomized trials comparing the use of mesh to native tissue repair in POP surgery have now shown better anatomical but similar functional outcomes, and meshes are associated with more complications, in particular for transvaginal mesh implants. POP is not a life-threatening condition, but a functional problem that impairs quality of life for women. The old adage "primum non nocere" is particularly appropriate when dealing with this condition which requires no treatment when asymptomatic. It is currently admitted that a certain degree of POP is physiological with aging when situated above the landmark of the hymen. Treatment should be individualized and the use of mesh needs to be selective and appropriate. Mesh implants are probably an important tool in pelvic reconstructive surgery, but the ideal implant has yet to be found. The indications for its use still require caution and discernment. This review explores the reasons behind the introduction of mesh augmentation in POP surgery, and aims to clarify the risks, benefits, and the recognized indications for its use.
\end{abstract}

Keywords: pelvic organ prolapse surgery, mesh surgery, review, pelvic floor, mesh implants

\section{Introduction}

Surgery for pelvic organ prolapse (POP) is common among women. The lifetime risk of undergoing at least one surgical intervention by the age of 80 was estimated to be between $6.3 \%$ and $19 \%$, with $30 \%$ of women requiring reoperation for recurrence. ${ }^{1,2}$ The prevalence of reoperation after primary pelvic reconstructive surgery reported in some articles was even higher $(43 \%-58 \%) .{ }^{3,4}$ Over the past decade, in an attempt to improve outcomes based on this high estimate of recurrence, surgeons have increasingly used prosthetic materials for the treatment of POP. The use of mesh is nevertheless associated with a non-negligible risk of complications (vaginal erosions and potential consecutive infections, granulomas, dyspareunia, vesico-vaginal fistulas, chronic pain) thereby potentially reducing the quality of life of women and leading to additional surgeries. ${ }^{5-8}$ Based on our clinical experience, we found that these high rates of recurrence were probably overestimated. The results of previous studies addressed both urinary incontinence and POP thus overestimating the risk of 
reoperation for POP alone. After closer examination of the references cited in some of these articles, we found that the high recurrence rates resulted from studies including genital prolapse after Burch colposuspension which is not a primary POP surgery, but an anti-incontinence procedure. ${ }^{9}$ The aim of this article was to review surgical treatments of POP, and analyze the evidence for the use of mesh material in pelvic floor reconstructive surgery.

\section{True incidence and risk factors for reoperation of surgically treated POP}

The incidence and the risk factors for reoperation of surgically treated POP are of utmost importance in the development of mesh reconstructive surgery. Based on our clinical experience, we hypothesized that the risk of reoperation would be lower than some of the above mentioned estimates frequently cited in medical literature. ${ }^{1,9,10}$ We conducted a nested casecontrol study in a cohort of 1,811 women who were surgically treated for POP in our department over a 20-year period. We found that the incidence of POP reoperation was 5.1 per 1,000 women-years with a cumulative incidence of $5.6 \%$ and a mean duration follow-up of more than 11 years. ${ }^{11}$ This is much less than the $30 \%$ to $50 \%$ risk previously described. Significant risk factors were the presence of preoperative prolapse in more than two vaginal compartments, history of surgery for POP and/or urinary incontinence and the presence of sexual activity. We concluded that the risk of reoperation for recurrence was associated with a preexisting weakness of pelvic floor tissues, either due to genetic or traumatic factors. Mechanical factors associated with sexual activity may explain the increased risk of subsequent genital prolapse. It is also possible that sexually active women may overtly seek POP surgery, thereby explaining the higher risk of reoperation in this population, independently of age as shown by the multivariable model. Corroborating our results, recent studies reported lower rates (between $1.5 \%$ and $13 \%$ ) of reoperation for surgically treated POP and urinary incontinence. . $^{3,12,13}$ In two recent studies, the risk of POP recurrence after POP specific reconstructive surgery without use of prosthetic material was estimated to be between 3\% and 10\%. ${ }^{14,15}$

Very little is known of the factors associated with surgical failure. Data come from small studies where few risk factors are identified. Younger age, high body mass index and advanced preoperative prolapse (grade III-IV) were associated with an increased risk of reoperation in some studies. ${ }^{4,12,14}$ However, these results were contradicted by other studies in which these associations were not observed. ${ }^{2,3}$
In our study, we chose reoperation as a primary outcome because from our point of view it reflects symptomatic POP that requires treatment. Swift et al demonstrated that when the leading edge of vaginal wall was at or above the hymen, $98 \%$ of patients were asymptomatic. ${ }^{16,17}$ This is a very important concept, as success in POP surgery is consecutive to this definition. Most articles used anatomical stage 1 or 2 of POP as a criterion of success, but the main criterion is the absence of bulge or vaginal pressure associated with urinary, defecatory or sexual dysfunction. POP staying above the hymen as a threshold for success is better correlated with successful functional outcomes. Barber et al showed that the leading edge at the hymen as a definition of success was correlated with $94 \%$ of successful functional outcomes, no retreatment in $97 \%$ of cases and no bulge symptoms in $92 \%$ of patients. ${ }^{18}$

\section{Therapeutic approaches of POP}

The management of POP includes observation, pelvic floor rehabilitation, pessary use, and surgery. Among ambulatory women, less than 5\% present with POP beyond the hymen. Therefore, most POP are asymptomatic and do not require treatment. ${ }^{19-22}$ POP is progressive until menopause, after which either progression or regression is possible. This was demonstrated in a cohort of 249 women with mean age of 68 years who were followed over a 3 -year period. In this study, POP increased by at least $2 \mathrm{~cm}$ in $10 \%$ of women, and regressed by the same amount in 3\% of women. Regression was more frequent for early stages $(25 \%$ in stage 1$) .^{23,24}$

Pelvic floor muscle exercise (PFME) may result in regression of POP stage, but mainly improves associated functional symptoms as demonstrated in two recent randomized controlled trials. ${ }^{25,26}$ Braekken et al reported improvement of one stage with the POP-Q system in $19 \%$ of women in the intervention group compared to $8 \%$ in the controls $(11 \%$ risk difference). ${ }^{26}$ During subgroup analysis, this effect was statistically significant for women with POP above or at the hymen but not for those presenting the distal part of POP below the hymen. However, in the latter subgroup, $0 \%$ of women in the intervention group (PFME) worsened their POP stage compared to $20 \%$ in the controls, thus showing potential benefits in preventing progression of POP. This effect was not observed in the Hagen et al study. ${ }^{25}$ Both studies showed significant improvement in prolapse, as well as bowel and urinary symptoms at 6 and 12 months. However, long-term benefits are still unknown. In the Hagen et al study, the number of women who required further treatment was reduced in the PFME group compared to controls 
( $24 \%$ versus $50 \%$ ), but there was no difference between groups in the number of women who required further pelvic floor reconstructive surgery $(11 \%$ in the intervention compared to $10 \%$ in the control group respectively). Further studies are needed to show if PFME could help avoid surgery in selected patients.

Vaginal pessaries represent the main alternative to surgical treatment for POP. These silicone devices which come in a variety of shapes and sizes require regular removal and cleansing. They should be offered to all women presenting with POP as about half of them will continue to use them at medium term (1-2 years). ${ }^{27,28}$ The most common side effects are malodorous vaginal discharge, bleeding, erosions and ulcers, de novo incontinence and interference with sexual intercourse, thereby inciting preference of surgery for some women. Most minor complications however occur in the setting of vaginal atrophy and can be treated or prevented with associated local estrogen therapy.

Surgical treatment is indicated in women with symptomatic POP when conservative management has failed or has been declined. There is no indication for repair of asymptomatic POP as an isolated procedure where surgical correction is of uncertain benefit and adds peri- and post-operative risks. The objective of our treatment should always aim to restore quality of life and comfort. As previously mentioned, in older women a certain degree of POP is physiological and should not be treated when asymptomatic..$^{29,30}$

There are numerous surgical techniques for the treatment of POP, including vaginal and abdominal approaches with or without graft materials. Pelvic support may be disrupted during pregnancy and particularly after vaginal delivery, and it is commonly accepted that POP surgical treatment should be postponed or treated conservatively until childbearing is complete. Women of young age are at a higher risk of POP recurrence and are at a lower risk for surgical complications. They should therefore be treated with the more efficient procedures. Obese women have a higher risk of recurrence and should also benefit from the most effective procedures. ${ }^{4,12}$

The choice of primary surgical procedure includes a variety of possibilities:

- Surgery can be reconstructive or obliterative. Reconstructive procedures should be the first option, but in case of increased risk due to comorbidity and the absence of future intercourse, obliterative vaginal procedures such as colpocleisis are an option.

- When there is an apical defect, a decision has to be made whether total or subtotal hysterectomy, needs to be performed as part of the procedure.
- The choice of the surgical route (abdominal or vaginal) depends predominantly upon the optimal approach for the treatment of single or multiple sites of prolapse, patient preference, and risk factors for recurrence.

- Stress urinary incontinence (SUI), and sometimes anal incontinence, often coexists with POP. When planning POP repair, treatment of SUI and/or anal incontinence must also be addressed.

- Surgical meshes have been used in abdominal POP repair (sacrocolpopexy) for decades. Their use in transvaginal POP surgery has increased over the last decade, but their safety has been questioned. A choice has to be made between native tissue repairs with standard vaginal surgery, and mesh associated repairs either through the vaginal or the abdominal route.

\section{Clinical background of mesh use in POP reconstructive surgery}

The main rationale for mesh use was the hypothetical reduction of the high recurrence after standard vaginal surgery without mesh, with an average $30 \%$ rate of reoperation. ${ }^{1}$ This rate was often cited in subsequent publications as an incentive to justify and sustain this new strategy. We know now that this initial postulate was probably wrong, but under mounting pressure from the industry, production of meshes and new procedures were introduced before evidence of its benefit was established. In the 1990s, based on success in the treatment of abdominal hernia and of SUI with the use of midurethral synthetic slings, gynecological surgeons began using surgical meshes for pelvic floor reconstructive surgery. ${ }^{31}$ The supposedly high failure rate of standard pelvic floor reconstructive surgery using native tissue combined with the success observed in these two medical conditions boosted the use of prosthetic material to treat POP. Figure 1 shows the increase in publications concerning mesh use in the end of the 20th and the beginning of the 21 st century. Twenty years ago, abdominal hernia repair using plication of fascia transversalis (Shouldice repair) was standard in general surgery with a $4 \%$ to $6 \%$ rate of recurrence. Various mesh repairs were proposed to reduce the incidence of recurrence, with a $50 \%$ to $75 \%$ reduction rate; however, the absolute difference was low $(2 \%-4 \%){ }^{32-34}$ Until recently, analogously to what is being shown for vaginal meshes, articles raised the question of the validity of mesh use for such a minimal absolute benefit in term of recurrence. Emergence of new complications with mesh use in the treatment of inguinal hernia - in particular mesh related pain and nerve entrapment - were of particular concern. If the incidence of native tissue hernia repair pain 


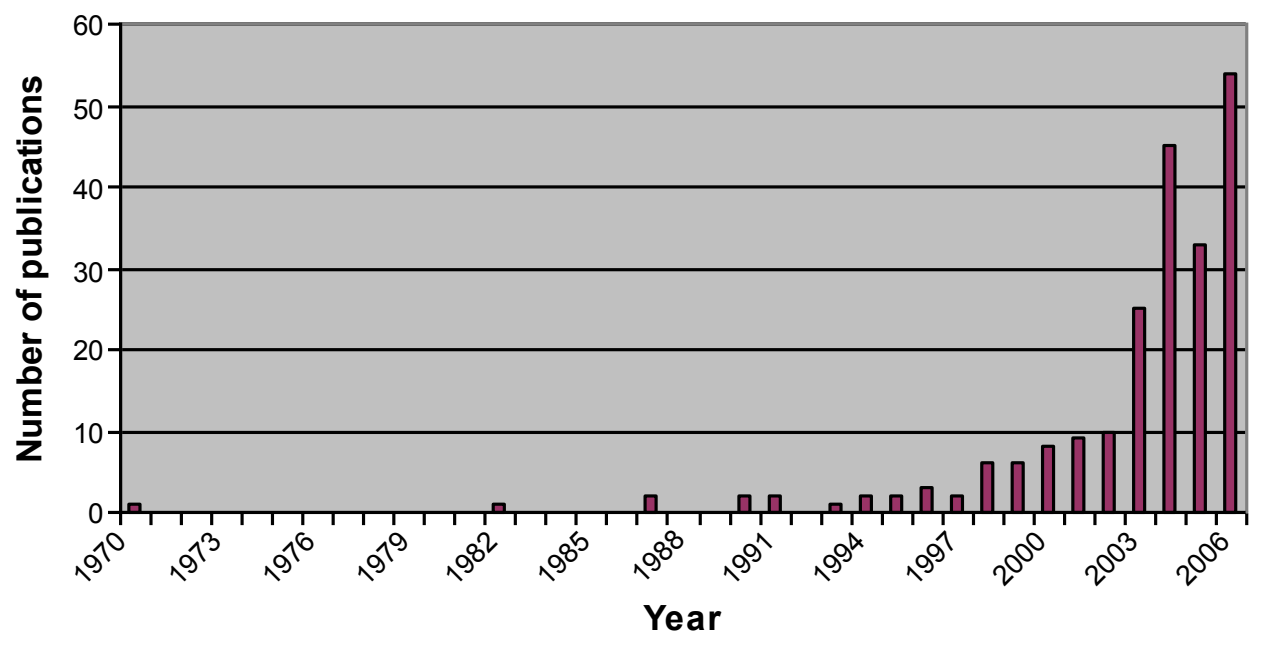

Figure I Number of publications indexed in Medline regarding the use of mesh for pelvic organ prolapse repair from 1970 until 2007.

was $2 \%$ to $4 \%$ with a risk of recurrence of $4 \%$ to $6 \%$, the use of mesh reduced the risk of recurrence to $2 \%$ but increased mesh related inguinodynia up to $21 \% .^{32}$

\section{Differences between abdominal hernia and pelvic floor repairs}

Sexual function represents a significant difference when comparing abdominal wall with vaginal wall repair. Vaginal skin is a thin mucosa, highly innervated and vascularized in comparison to the abdominal wall. Sexual health is an essential component of a woman's well-being and any kind of POP surgery should take this dimension into account. Anatomical outcome of POP surgery is probably not the most important parameter that needs to be evaluated with POP reconstructive surgery. The most important consideration is to restore normal function, with disappearance of vaginal bulge, pelvic pressure but also normalization of urinary, defecatory, and sexual function.

\section{Reconstructive material used in pelvic floor reconstructive surgery}

The principle of using grafts in reconstructive surgery is to reinforce existing tissue. The material must be safe, biologically compatible, and must provide both anatomic and functional results, especially in pelvic floor surgery. The ideal material should be chemically and physically inert, noncarcinogenic, mechanically strong while remaining flexible, non-allergenic, non-inflammatory, and non-modifiable by body tissue. It must be sterile, convenient to use and affordable, with minimal risk of subsequent infection or rejection. Currently, no graft has all these properties. Moreover, in POP surgery, the optimal implant should restore normal anatomy and function to the vagina and the surrounding pelvic organs and have longer longevity than autologous tissue. Once implanted, it should not result in adhesion formation on the visceral surfaces.

The first synthetic mesh produced for urinary incontinence treatment received clearance from the US Food and Drug Administration (FDA) in 1996. Polypropylene mesh $\left(\right.$ Marlex $^{\circledR}$ ) was thereby used for the treatment of cystocele with good results during the same year. ${ }^{35}$ Due to exposure rate observed with non-absorbable mesh, fully absorbable meshes were introduced by the end of the 1990s, but because of disappointing long-term results, they rapidly became unpopular. ${ }^{36,37}$ The first mesh product for pelvic reconstructive surgery approved by the FDA $\left(\right.$ Gynemesh $^{\circledR}$ ) followed in 2002. ${ }^{38}$ Subsequently surgical mesh products evolved into "kits" that included tools to help insert the synthetic graft material. The first mesh kits were cleared by the FDA in 2004 and marketed by the American Medical Systems (San Jose, CA, USA) under the names of Apogee and Perigee. Since then, there have been numerous new POP reconstructive mesh devices introduced in the USA and around the world. In 2010, of the 300,000 POP surgeries in the USA, one-third used mesh. Three quarters of the mesh procedures were transvaginal surgeries (approximately 75,000 procedures). ${ }^{39}$

Currently, there are four kinds of materials used in reconstructive surgery: synthetic mesh, autografts, allografts, and xenografts.

Autografts are harvested from the patient who is undergoing the procedure. Their use is limited by morbidity associated with tissue harvesting as well as the inconsistent quantity and quality of the material. The most commonly used autografts are fascia lata and rectus fascia. ${ }^{40,41}$ A clear advantage is that host response is not problematic. 
Allografts are most often processed from cadaveric fascia of human donors. The material has to be rendered nonimmunogenic by a cleaning procedure which removes cells without damaging the connective tissue scaffold. Use of this material eliminates the morbidity associated with autologous fascia harvest but presents a potential risk of donor-related viral infection. Their performance is also consistently less beneficial when compared to autologous fascia and synthetic meshes.

Xenografts consist of acellular extracts of collagen harvested from non-human (bovine, porcine) sources. They pose a theoretical risk of infection. Some patients might refuse their implantation due to religious beliefs or cultural barriers.

Synthetic meshes are available in both absorbable and non-absorbable forms. The advantages are availability and lack of risk of donor to host infectious disease transmission. However, infectious and erosive complications exist due to bacterial colonization of foreign body.

\section{Host response}

The histological response to reconstructive material used in surgery depends upon the physical and structural properties of the prosthesis. Host response comprises several stages:

- Incorporation: infiltration of reconstructive material by host cells, allowing neovascularization and collagen deposition.

- Encapsulation: collagen and connective tissue deposit at the periphery of the material.

- Mixed response: incorporation occurs at graft pores and encapsulation occurs around the remaining material.

- Resorption: material is replaced by host neo-connective tissue.

Due to similarities with native tissues, biologic grafts are more likely to undergo tissue remodeling and thereby are less likely to cause erosion. They can however be costly, in limited supply, and carry perioperative morbidity or theoretical infectious disease transmission. Therefore, synthetic meshes are the most popular choice both in general and in POP reconstructive surgery.

The ideal mesh should incur minimal inflammatory reaction, followed by vascular and fibroblastic ingrowths. The key factors for host response to synthetic meshes are pore size and weave.

\section{Synthetic grafts classification and properties}

Host response depends on absorbability, pore size (space between filaments), weave (mono or multifilament), and weight (density). Both absorbable and non-absorbable meshes cause initial and chronic inflammatory reactions after implantation.

Absorbable materials elicit a chronic foreign body reaction and promote fibroblast activity. After complete absorption, the material is replaced by collagen-rich connective tissue. ${ }^{42}$ One disadvantage is that the resultant scar tissue weakens after the material is absorbed and therefore may not provide long-term repair strength. ${ }^{43}$ Some potential advantages of absorbable materials over non-absorbable materials are that they are less likely to become infected and are less harmful to viscera. ${ }^{44}$

Non-absorbable prosthetic materials, such as polypropylene which is widely used, are associated with more connective tissue reaction. Repair strength is increased by the presence of the implant and greater scar formation.

Pore size influences cellular infiltration, risk of infection, and mesh density and flexibility. ${ }^{45}$ Pore size greater than 75 microns is considered macroporous, whereas that less than 10 microns is considered microporous. Pore size determines which cells (macrophages versus bacteria) can enter the mesh and is considered the most important mesh characteristic. Most bacteria measure less than 1 micron in diameter and granulocytes and macrophages measure more than 10 micron in diameter. Seventy-five microns is considered a significant measurement, because this pore size allows entry of fibroblasts, macrophages, blood vessels, and collagen fibers, thus minimizing risk of infection and optimizing collagen infiltration. Pore size also affects flexural rigidity which is decreased with larger pore size. Micropores ( $<10$ microns) result in restriction of fibroblast and immune cell colonization to the material surface. Therefore, collagen and connective tissue deposition occurs at the periphery rather than by infiltration of host cells, resulting in encapsulation. Microporous materials increase risk for infection as large immune cells cannot infiltrate the interstices to phagocyte bacteria. ${ }^{46}$

Synthetic mesh implants are classified as mono or multifilament. Multifilament materials have interstices of less than 10 microns. These spaces theoretically allow bacteria to enter and replicate, but prevent penetration of host immune cells thus increasing the risk of infection.

Mesh weight is another parameter that needs to be considered for synthetic materials. Meshes with larger pores have a lower weight and are more elastic. Light-weight materials may be less prone to infection and consecutive erosion.

Based on these characteristics, non-absorbable synthetic meshes are classified with respect to their pore size and filamentous nature in four subtypes (Table 1) ${ }^{47}$ Type I meshes of low weight represent the preferred option for pelvic floor reconstructive surgery at present time. 
Table I Classification of synthetic meshes

\begin{tabular}{ll}
\hline Type of mesh & Characteristics \\
\hline I & Macroporous ( $>75$ microns) and monofilamentous such as polypropylene and theoretically makes the best implants. \\
& It is further divided into heavy-, mid-, and light-weight materials $\left(e g\right.$, Prolene $\left.{ }^{\circledR}\right)$. \\
II & Microporous ( $<10$ microns) such as polytetrafluoroethylene $\left(\mathrm{eg}, \mathrm{Gore-Tex}{ }^{\circledR}\right)$. \\
III & Macroporous material $(>75$ microns) with either multifilamentous or microporous components such as \\
& polyethylene (eg, Mersilene $\left.{ }^{\circledR}\right)$. Histologic behavior is similar to type II materials. This category includes some \\
& polypropylene materials with microporous components such as Ob Tape ${ }^{\circledR}$ and IVS Tunneler both of which were \\
& associated with an increased rate of erosion and infection. \\
IV & Submicronic (pore size $<$ I micron) (eg, polypropylene sheet Cellgard $\left.{ }^{\circledR}\right)$ and associated with type I mesh for \\
& adhesion prevention but is not commonly used in gynecological surgery. \\
\hline
\end{tabular}

\section{Effectiveness of grafts in specific gynecologic procedures} Anterior compartment repair

Anterior vaginal wall defects are the most common site of POP followed by posterior and apical defects affecting respectively $34 \%, 18 \%$, and $14 \%$ of women in the Women's Health Initiative study. ${ }^{48}$ Most mesh reports focus on treatment of anterior compartment defects. Historically, anterior colporrhaphy with plication of perivesical fascia was the standard procedure with success rates ranging from $80 \%$ to $100 \%$ in retrospective series. ${ }^{49,50}$ The move to prosthesis use was initiated by the Olsen et al report of $29.2 \%$ of reoperation rate following POP and/or incontinence surgery and the Weber et al report of a $70 \%$ failure rate after native tissue repair. ${ }^{1,37}$ Recent reanalysis of the latter study using the hymen as a threshold for success reported very different outcomes, with only $10 \%$ of anatomical recurrence beyond the hymen, $5 \%$ of symptomatic recurrence and less than $1 \%$ of reoperation for standard native tissue repair. ${ }^{37,51}$ The original trial compared three techniques of anterior repair (two without mesh and one with absorbable mesh) and defined recurrent prolapse as greater than stage 1 , therefore overestimating the rate of clinically significant recurrence.

\section{Synthetic graft}

The use of polypropylene synthetic mesh in the treatment of anterior compartment prolapse was compared to standard native tissue repair in two recent randomized controlled trials with similar results. ${ }^{52,53}$ In the Nieminen et al trial, 202 women, 97 in the colporrhaphy group and 105 in the synthetic mesh group, showed better anatomical outcomes at 3 year follow-up in the mesh group but no significant difference in subjective outcomes. ${ }^{52}$ The erosion rate was very high in the mesh group (19\%). Of the 389 women who were randomly assigned by Altman et al to a study treatment, 200 women underwent a transvaginal POP mesh repair and 189 underwent traditional colporrhaphy. ${ }^{53}$ At 1 year follow-up, anatomical outcome was significantly better in the mesh group, but there was no difference in the subjective outcome. Subsequent surgery to address mesh related complication was $3 \%$ compared to $0.5 \%$ for recurrence in the standard colporrhaphy group. There were more perioperative and post-operative adverse events in the mesh group. De novo SUI was also significantly higher in the mesh group. Recent reviews conclude that with the use of synthetic meshes in the treatment of anterior POP, there is an improved anatomical outcome but no difference in functional outcomes, with potentially more complications, in particular a high rate of vaginal mesh exposure of around $10 \% .^{54,55}$

\section{Absorbable mesh}

Absorbable mesh use was adopted in order to achieve equivalent success rate with fewer complications. Very few studies have addressed this question. ${ }^{37,56,57}$ Augmentation with Polyglactin 910 reduced the rate of recurrence but was also associated with mesh erosion in two of the three trials. Some authors have advocated the use of coated mesh to reduce the risk of mesh erosion. A recent trial comparing anterior colporrhaphy with collagen-coated transvaginal mesh for anterior vaginal wall prolapse showed, on the contrary, a high risk of erosion $(13.3 \%){ }^{58}$

\section{Biologic grafts}

In a small series of 47 patients, an autologous vaginal patch tucked under the anterior compartment repair had a 93\% success rate at mean follow-up of more than 1 year. ${ }^{59}$ The use of cadaveric fascia to correct anterior compartment prolapse compared to anterior colporrhaphy alone was evaluated in a randomized controlled trial. ${ }^{60}$ At 1 year, this study failed to demonstrate that the addition of fascia lata improved outcomes. No complications were reported, but concerns regarding latent infectious disease or residual antigenicity causing host graft rejection remains. For this reason porcine 
dermis has been used in some studies with contradictory results. A retrospective study comparing standard anterior colporrhaphy, porcine dermis augmentation, and polypropylene graft showed success rates at 13 months of $94 \%, 64 \%$, and $96 \%$ respectively with a $21 \%$ rate of vaginal extrusion in the porcine dermis group. ${ }^{61}$ A multicenter randomized trial comparing anterior colporrhaphy augmented with porcine dermis to anterior colporrhaphy with native tissue showed a success rate of $93 \%$ in the former group compared to $81 \%$ in the latter with an erosion rate for porcine dermis of $1 \%{ }^{62}$ A randomized controlled trial compared three operations: anterior colporrhaphy, porcine dermis graft, and polypropylene graft for anterior augmentation. The objective success rate of $86 \%$ was significantly better after the use of polypropylene mesh compared to $52 \%$ for porcine dermis and $53 \%$ in the native tissue repair group. ${ }^{63}$ The subjective failure rate was not significantly different and graft erosion rates were $13.8 \%$ in the polypropylene group and $4.3 \%$ in the porcine dermis group. Another recent small randomized controlled trial comparing anterior prolapse repair using porcine small intestine submucosa mesh-augmented procedure or the same repair without mesh did not show any significant difference in the primary outcome which was anatomical cure. ${ }^{64}$

It transpires from these studies and from the Cochrane review that objective success rates for anterior compartment repair are better with all synthetic meshes, but that there is no significant difference in terms of subjective success. ${ }^{54}$ The benefit of absorbable mesh and biologic grafts is not proven. All mesh types are associated with some form of mesh related complication that can cause reoperation.

\section{Posterior compartment repair}

Only one trial specifically compared posterior mesh repair to traditional repair ${ }^{65}$ and showed that mesh repair had worse anatomic outcomes than traditional repair. Two other trials combining anterior and posterior repair also found no additional benefit of mesh augmentation in the posterior compartment. ${ }^{57}$ So far, no studies have shown any benefit of mesh in posterior compartment repair. Traditional midline fascial plication has a high anatomical cure rate of between $80 \%$ to $90 \%$. Concomitant levatorplasty should be avoided to reduce the risk of dyspareunia in sexually active women. ${ }^{57,66,67}$

\section{Apical prolapse}

There is consistent and reproducible evidence that abdominal sacrocolpopexy (ASC) using mesh has a higher success rate than vaginal surgery along with less post-operative dyspareunia. Vaginal procedures to treat apical defect mainly consist of sacrospinous ligament suspension, or uterosacral ligament suspension of vaginal apex. A few randomized controlled trials compared ASC with vaginal surgery, and all of the trials demonstrated significantly improved anatomical but also functional outcomes. ${ }^{68-70} \mathrm{~A}$ review showed success rates of $78 \%$ to $100 \%$ for ASC, reoperation rates of $4.4 \%$, and erosion rates of $3.4 \% .^{70}$ Erosion rates may be increased up to $27 \%$ if total concurrent hysterectomy is performed compared to $1.3 \%$ without hysterectomy. ${ }^{71}$ Apical prolapse is also often associated with anterior or posterior prolapse which can therefore be treated concomitantly through the abdominal route. However, treatment for isolated anterior or posterior prolapse is usually performed transvaginally. ${ }^{54,55,72}$

Some surgeons have attempted to decrease mesh complication associated with ASC using biological material instead of synthetic mesh. All biological materials - whether allograft or xenograft - produced inferior anatomical outcomes without decreased graft complications. ${ }^{73-77}$

The use of a transvaginal mesh in apical prolapse was evaluated in only two randomized trials. When comparing uterosacral colpopexy and native tissue repair with a monofilament kit $\left(\right.$ Prolift $\left.^{\circledR}\right),{ }^{78}$ subjective failure rates were similar between the two groups $(9.1 \%$ in the native tissue group compared to $3.8 \%$ in the mesh group), but with $15.6 \%$ of subsequent surgical interventions in the mesh group compared to $0 \%$ in the conventional surgery group at 1 year follow-up. Indications for reoperation were mesh exposure and recurrent prolapse. Among the 32 patients in the mesh group there were two inadvertent cystotomies and one transfusion for hemorrhage compared to none in the native tissue repair group. When comparing laparoscopic sacral colpopexy (LSC) to total vaginal mesh kit, a $77 \%$ objective success rate was found in the LSC group compared to $43 \%$ in the vaginal mesh kit group. ${ }^{79}$ Reoperations were also significantly higher in the vaginal mesh group (22\% compared to $5 \%$ in LSC group).

ASC, and nowadays LSC, performed with polypropylene mesh reinforcement are considered the gold standard to correct apical vaginal prolapse and may also correct high cystocele and rectocele. Further data are needed to assess its performance with preservation of the uterus, a procedure which is now frequently performed.

Although the outcomes for ASC or LSC with synthetic meshes are favorable, it is necessary to understand its risk and possible complications. The overall mesh erosion rate described in one review was $3.4 \%$ but may vary according to the type of mesh used. ${ }^{70}$ Studies reporting the use of type I mesh show very low rates of erosion $(0.5 \%) .{ }^{46}$ Concomitant 
total hysterectomy should be avoided and if necessary, a supracervical hysterectomy should be performed. Besides mesh complications, gastro-intestinal complications including ileus and small bowel obstruction are of concern. Chronic mesh pain syndrome (CMPS) and dyspareunia were rarely reported. Peri-operative hemorrhage during dissection of the promontory and bladder or rectum injury during pelvic floor dissection may also occur. To limit the risks associated with the dissection of the promontory during sacrocolpopexy, Kapandji described in 1967 an alternative technique with lateral suspension of apical prolapse. ${ }^{80}$ It consisted of fixation of the anterior vagina and the uterus isthmus with a mesh to the anterior superior iliac bone. In 1994, Cornier and Madelenat described a new development based on Kapandji's technique by laparoscopy. ${ }^{81}$ The technique was progressively modified by Dubuisson et al with a higher transparietal tension-free lateral suspension, $5 \mathrm{~cm}$ above the anterior superior iliac spine, and showed similar results to those of sacrocolpopexy and sacrohysteropexy. ${ }^{82-84}$ We further developed this technique with robotic assistance which allowed us to avoid the transparietal passage of the mesh which is one of the steps of the standard laparoscopic technique thereby further reducing potential complications to abdominal wall nerves. ${ }^{85}$

\section{Complications of mesh materials}

Despite initially reassuring data, concerns regarding the safety of transvaginal meshes arose in 2008 with the first FDA notification that it had received more than 1,000 reports of mesh associated complications, some of which may not be correctable surgically (US FDA, March 9 available at www.fda.gov). ${ }^{86}$ In 2011, the FDA released two more communications highlighting safety concerns surrounding meshes. The update stated that there were 1,503 reported complications associated with mesh devices for POP from 2008 to 2010. The most common complications included mesh erosion through the vagina, pain, infection, bleeding, dyspareunia, organ perforation, and urinary problems. There were also reports of recurrent prolapse, neuromuscular problems, vaginal scarring with shrinkage, and emotional distress. Many of these complications required further surgical intervention. The FDA stated that it is not clear that mesh augmentation is more effective when compared to native tissue repair. Expert committee opinion recommended that mesh augmentation be reserved for high risk individuals in whom benefit outweighs potential risks. ${ }^{38}$ The follow-up of most studies is close to 1 year and there are few studies with follow-up for a longer period. Therefore, the number of adverse events is probably underestimated.
The most commonly reported mesh complication was mesh erosion into the vagina which may require multiple surgeries with persistent sequelae despite mesh removal. ${ }^{87}$ In a systematic review of Abed et al vaginal POP repair with mesh was associated with a summary incidence of $10.3 \%$ of erosion. The incidence did not differ between non-absorbable synthetic mesh and biologic graft material. ${ }^{88}$

A systematic review that included more than 7,000 women concluded that abdominal POP surgery with mesh such as sacrocolpopexy resulted in lower rates of mesh complications compared to vaginal POP surgery with a median mesh erosion rate of $4 \%$ during a 2 -year follow-up. ${ }^{89}$ Vaginal surgery with mesh to correct apical prolapse is associated with a higher rate of complication requiring reoperation, when compared to sacrocolpopexy or traditional repair $(7.2 \%$ versus $4.8 \%$, versus $1.9 \%$ respectively)..$^{90}$

Mesh contraction is another specific adverse event causing vaginal tightening and consecutive pain after POP repair with mesh. ${ }^{91}$ It can also occur after traditional repair but seems to be increased in case of mesh augmentation.

CMPS develops in a small number of patients but can be very distressing. It is characterized by pain following mesh insertion persisting beyond the routine post-operative period (more than 90 days) and takes a chronic course. ${ }^{8,92}$ Pain is refractory to medical and surgical treatment and is disproportionate to physical examination findings. Since CMPS is a complex multi-organ systemic process, resulting from abnormal neuronal activation with sensitization of pain pathways in the spinal cord and central nervous system, along with pelvic organ cross-talk, treatment is challenging. Patients often suffer from hyperalgesia. The cascade of events is not entirely reversible by mesh removal. Risk factors for CMPS development include mesh material, surgical technique, and host factors. Treatment will sometimes include mesh removal but also requires a multidisciplinary approach similar to other chronic pain syndromes.

Infection, dyspareunia, urinary problems, and re-surgery are other common adverse events associated with mesh POP repair but also occur with traditional repair. There is no evidence that organ perforation, hemorrhage, and hematoma occur more often with mesh repair. However, mesh erosion into the bladder or rectum are specific adverse events which can lead to fistula formation and the need for additional corrective surgery.

De novo SUI seems to occur more frequently after anterior repair with mesh compared to traditional native tissue repair. ${ }^{53}$ This is not the case with mesh use by the abdominal route during sacrocolpopexy. There are nevertheless very 
few studies comparing sacrocolpopexy to standard vaginal surgery and all of them included SUI procedures, therefore making any comparison difficult. In two prospective randomized studies comparing these methods, both found less SUI in the sacral colpopexy group. ${ }^{68,93}$ In a randomized trial comparing LSC to total vaginal mesh for vaginal vault prolapse, SUI was also less frequent in the sacrocolpopexy group compared to the vaginal group. ${ }^{79}$ However, both groups included associated SUI procedures in all women with SUI or occult stress incontinence preoperatively, but with different techniques (colposuspension in the LSC group and suburethral tape in the vaginal group). It is therefore very difficult to draw any firm conclusion. The risk of post-operative SUI is probably not associated with the use of mesh per se but more likely with the type of support achieved during pelvic reconstructive surgery.

\section{Risk factors for erosion}

Mesh erosion represents one of the main complications of mesh use in POP reconstructive surgery. Few studies have analyzed the risk factors for erosion. One study clearly identified tobacco use as a risk factor. ${ }^{94}$ Erosion rates with synthetic meshes vary with the properties of the mesh. For example in ASC, vaginal mesh erosion has been reported to be $2 \%$ with polypropylene compared to higher rates of up to $11 \%$ with microporous multifilament meshes such as GoreTex and Mersilene. ${ }^{95,96}$ In our local series of transobturator meshes for the treatment of SUI, we also demonstrated the importance of characteristics inherent to mesh material as a risk factor for vaginal erosion. ${ }^{97}$

Other potential risk factors are diabetes, obesity, age, associated total hysterectomy, and surgical experience.

\section{Discussion on POP reconstructive surgery}

The risk of reoperation for POP recurrence in pelvic reconstructive surgery without mesh is lower than previously estimated, being close to $10 \%$ rather than the $30 \%$ to $50 \%$ as previously estimated. ${ }^{3,11-15}$ An extensive review of medical literature shows that there are currently no proven benefits in terms of functional outcomes with the use of transvaginal mesh, but on the contrary, mesh use is associated with more adverse events and consequently potential reoperations. Improved anatomical outcome is an insufficient criterion to use mesh in POP reconstructive surgery, especially in the presence of adequate demonstration of comparably successful subjective outcomes without mesh. Mesh use in transvaginal surgery should be avoided, at least as first line treatment.
POP is a condition that affects quality of life but is never a life-threatening situation. Conservative measures should systematically be discussed before surgery. Therapeutic approaches should always aim to restore normal function and enhance quality of life. The use of mesh should be carefully evaluated and treatment needs to be individualized. Transvaginal mesh surgery is associated with multiple potential complications with adverse events requiring additional interventions which can be challenging. Indications for the use of transvaginal mesh for POP reconstructive surgery are currently rare. They still may represent an alternative in specific cases of recurrence after primary standard vaginal surgery or in patients where the abdominal route or laparoscopies are contraindicated. The experience of the surgeon probably plays a major role in reducing the rate of complications..$^{98,99}$ For this reason, these operations should only be performed by trained pelvic surgeons. In case of recurrence, the use of mesh by the abdominal route has the best outcomes. A secondary procedure using native tissue repair is also possible with limited adverse events if life expectancy is short.

For the treatment of apical compartment prolapse, abdominal (laparoscopic whenever possible) cure with mesh is an appropriate solution. Mesh use seems to be safer in this situation and shows favorable functional outcomes and improved sexual function when compared to standard vaginal surgery. Hysterectomy should probably be avoided, or if performed, should be subtotal with cervix conservation to limit the risk of vaginal erosion.

For isolated anterior or posterior compartment prolapse, native tissue repair with fascia plication is probably the primary method of choice. The use of mesh in these situations, although resulting in better anatomical outcome for anterior repair, is not indicated.

Diabetes and heavy smoking represent risk factors for erosion and mesh use should be avoided whenever possible. Young age, obesity, constipation, and chronic cough probably increase the risk of recurrence, but these factors should not radically change our therapeutic approach in case of monocompartment POP.

When mesh use is indicated, a type I macroporous ( $>75$ microns) and monofilamentous mesh such as polypropylene theoretically makes the best implant.

When planning POP surgery, one should always discuss the issue of post-operative sexual function. POP obliterative procedures (colpocleisis) represent a safe and simple alternative in older women who are not sexually active especially in the setting of comorbidities and short life expectancies. Alternative conservative therapies such as pessary use should also 
Table 2 Pelvic organ prolapse (POP) reconstructive surgery strategies according to anatomical defects and patient characteristics

\begin{tabular}{|c|c|c|}
\hline Type of POP & Specificity & Type of surgery \\
\hline \multirow[t]{2}{*}{ Anterior } & Central defect & Vaginal reconstructive surgery with native tissue \\
\hline & Primary case & \\
\hline \multirow[t]{4}{*}{ Anterior } & Paravaginal defect & Abdominal (laparoscopic) reconstructive surgery \\
\hline & Recurrent case $^{a}$ & with mesh \\
\hline & Increase in risk factors ${ }^{\mathrm{b}}$ & \\
\hline & Associated apical prolapse & \\
\hline \multirow[t]{6}{*}{ Apical } & Long life expectancy & Abdominal (laparoscopic) reconstructive surgery \\
\hline & Intensive physical activities & with mesh \\
\hline & Intercourse & \\
\hline & Recurrence & If hysterectomy, prefer subtotal hysterectomy \\
\hline & Short vagina & \\
\hline & Increase in risk factors ${ }^{b}$ & \\
\hline \multirow[t]{5}{*}{ Apical } & Old patient with short life expectancy & Vaginal reconstructive surgery with native tissue \\
\hline & Reduced physical activities & and associated apex suspension (sacrospinous \\
\hline & Absence of intercourse & fixation or utero-sacral ligament suspension) \\
\hline & Primary case & with or without vaginal hysterectomy \\
\hline & Sufficient vaginal length & \\
\hline \multirow[t]{2}{*}{ Posterior } & Primary case & Vaginal reconstructive surgery with native tissue \\
\hline & Recurrence & \\
\hline \multirow[t]{5}{*}{ Total eversion } & Old patient with short life & Colpocleisis \\
\hline & expectancy & \\
\hline & No intercourse & \\
\hline & High operative risk due to & \\
\hline & co-morbidities & \\
\hline
\end{tabular}

Notes: aln case of recurrence involving only the anterior compartment, a second vaginal surgery with native tissue is also possible. ${ }^{b}$ Risk factors include: COPD, obesity, stubborn constipation, physical activities with straining. For patients with increased risk factors of POP recurrence, abdominal approach with mesh is probably the method of choice, but vaginal reconstructive surgery with native tissue is always possible for women with short life expectancy and for women where only one compartment is involved.

be discussed. For young and sexually active women with apical prolapse, the abdominal route seems the optimal approach as it limits the risk of dyspareunia. For posterior compartment prolapse in these patients, levator myorrhaphy should be avoided to limit the risk of dyspareunia. A therapeutic strategy for reconstructive POP surgery is proposed in Table 2.

\section{Future perspectives}

The ideal surgical treatment of POP is yet to be found. Current use of mesh is perfectible, and in order to reduce potential adverse effects and complications, research for the ideal mesh material is ongoing. Cell-based (stem cell) tissue engineering strategies may provide new alternatives to native tissue repair or mesh repair for POP. At present, research in urogynecology, is focused on SUI cell-based injection therapy to regenerate the urethral sphincter. ${ }^{100}$

Another recent advance in POP surgery is the use of robot-assisted surgery. Treatment of apical prolapse has evolved with the adoption by some gynecologists of robot assisted laparoscopic surgery. Although at present robotassisted surgery primarily provides advantages for the surgeon's ability and dissection with 3D vision, it does not improve the patient's outcomes when compared to initial standard laparoscopic technique. However, robotic surgery is continuing to evolve, with the use of smaller/single site incisions, and innovative technology, and future outcomes may also prove beneficial for patients. The combination of improved robotics and stem cell tissue engineering might open new perspectives in the future of POP surgery.

\section{Conclusion}

POP is a multifaceted condition which may be considered as physiological when the threshold of the hymen is not overcome and patients are asymptomatic. When symptomatic, it can affect quality of life and requires treatment. Women should always be offered conservative treatment (pessary use, physiotherapy) as first line therapy. If conservative treatment fails or if patients actively seek reconstructive surgery, standard vaginal surgery with native tissue is still a good alternative for isolated POP of the anterior and posterior compartment. The use of reinforcement material to improve outcome has to focus on function and must be discussed with caution. Patients need to be informed about their potential complications. The principal situation in which potential benefit outweighs the risk of complication is the use of mesh in the treatment of apical prolapse by the abdominal/laparoscopic route. 
Further research is ongoing to find the ideal material and the ideal approach for this condition, with the goal to preserve associated urinary, digestive, and sexual functions.

\section{Acknowledgment}

This manuscript is derived from a Privat-Docent thesis accepted by the faculty of Medicine of the University of Geneva Switzerland and was presented orally in a public lesson on October 27, 2014. The full manuscript is available on the website of Geneva University, only for members of the Swiss universities, and only until October 31, 2015 (http:// archive-ouverte.unige.ch/unige:41536).

\section{Disclosure}

The author has no conflicts of interest to disclose.

\section{References}

1. Olsen AL, Smith VJ, Bergstrom JO, Colling JC, Clark AL. Epidemiology of surgically managed pelvic organ prolapse and urinary incontinence. Obstet Gynecol. 1997;89(4):501-506.

2. Fialkow MF, Newton KM, Lentz GM, Weiss NS. Lifetime risk of surgical management for pelvic organ prolapse or urinary incontinence. Int Urogynecol J Pelvic Floor Dysfunct. 2008;19:437-440.

3. Clark AL, Gregory T, Smith VJ, Edwards R. Epidemiologic evaluation of reoperation for surgically treated pelvic organ prolapse and urinary incontinence. Am J Obstet Gynecol. 2003;189(5):1261-1267.

4. Whiteside JL, Weber AM, Meyn LA, Walters MD. Risk factors for prolapse recurrence after vaginal repair. Am J Obstet Gynecol. 2004;191(5): 1533-1538.

5. Jakus SM, Shapiro A, Hall CD. Biologic and synthetic graft use in pelvic surgery: a review. Obstet Gynecol Surv. 2008;63(4):253-266.

6. Yamada BS, Govier FE, Stefanovic KB, Kobashi KC. Vesicovaginal fistula and mesh erosion after Perigee (transobturator polypropylene mesh anterior repair). Urology. 2006;68(5):1121.e5-e7.

7. Fatton B, Amblard J, Debodinance P, Cosson M, Jacquetin B. Transvaginal repair of genital prolapse: preliminary results of a new tension-free vaginal mesh (Prolift technique) - a case series multicentric study. Int Urogynecol J Pelvic Floor Dysfunct. 2007;18(7):743-752.

8. Lin LL, Haessler AL, Ho MH, Betson LH, Alinsod RM, Bhatia NN Dyspareunia and chronic pelvic pain after polypropylene mesh augmentation for transvaginal repair of anterior vaginal wall prolapse. Int Urogynecol J Pelvic Floor Dysfunct. 2007;18(6):675-678.

9. Wiskind AK, Creighton SM, Stanton SL. The incidence of genital prolapse after the Burch colposuspension. Am J Obstet Gynecol. 1992; 167(2):399-404.

10. Kjolhede P, Noren B, Ryden G. Prediction of genital prolapse after Burch colposuspension. Acta Obstet Gynecol Scand. 1996;75(9):849-854.

11. Dallenbach P, Jungo Nancoz C, Eperon I, Dubuisson JB, Boulvain M. Incidence and risk factors for reoperation of surgically treated pelvic organ prolapse. Int Urogynecol J. 2012;23(1):35-41.

12. Diez-Itza I, Aizpitarte I, Becerro A. Risk factors for the recurrence of pelvic organ prolapse after vaginal surgery: a review at 5 years after surgery. Int Urogynecol J Pelvic Floor Dysfunct. 2007;18(11): 1317-1324.

13. Price N, Slack A, Jwarah E, Jackson S. The incidence of reoperation for surgically treated pelvic organ prolapse: an 11-year experience. Menopause Int. 2008;14(4):145-148.

14. Salvatore $\mathrm{S}$, Athanasiou $\mathrm{S}$, Digesu GA, et al. Identification of risk factors for genital prolapse recurrence. Neurourol Urodyn. 2009;28(4): 301-304.
15. Oversand SH, Staff AC, Spydslaug AE, Svenningsen R, Borstad E. Long-term follow-up after native tissue repair for pelvic organ prolapse. Int Urogynecol J. 2014;25(1):81-89.

16. Swift S, Woodman P, O’Boyle A, et al. Pelvic Organ Support Study (POSST): the distribution, clinical definition, and epidemiologic condition of pelvic organ support defects. Am J Obstet Gynecol. 2005; 192(3):795-806.

17. Swift S. Pelvic organ prolapse: is it time to define it? Int Urogynecol J Pelvic Floor Dysfunct. 2005;16(6):425-427.

18. Barber MD, Brubaker L, Nygaard I, et al. Defining success after surgery for pelvic organ prolapse. Obstet Gynecol. 2009;114(3): 600-609.

19. Swift SE. The distribution of pelvic organ support in a population of female subjects seen for routine gynecologic health care. Am J Obstet Gynecol. 2000;183(2):277-285.

20. Bradley CS, Nygaard IE. Vaginal wall descensus and pelvic floor symptoms in older women. Obstet Gynecol. 2005;106(4):759-766.

21. Tegerstedt G, Maehle-Schmidt M, Nyren O, Hammarstrom M. Prevalence of symptomatic pelvic organ prolapse in a Swedish population. Int Urogynecol J Pelvic Floor Dysfunct. 2005;16(6):497-503.

22. Rortveit G, Brown JS, Thom DH, Van Den Eeden SK, Creasman JM, Subak LL. Symptomatic pelvic organ prolapse: prevalence and risk factors in a population-based, racially diverse cohort. Obstet Gynecol. 2007;109(6):1396-1403.

23. Bradley CS, Zimmerman MB, Qi Y, Nygaard IE. Natural history of pelvic organ prolapse in postmenopausal women. Obstet Gynecol. 2007;109(4):848-854.

24. Handa VL, Garrett E, Hendrix S, Gold E, Robbins J. Progression and remission of pelvic organ prolapse: a longitudinal study of menopausal women. Am J Obstet Gynecol. 2004;190(1):27-32.

25. Hagen S, Stark D, Glazener C, et al. Individualised pelvic floor muscle training in women with pelvic organ prolapse (POPPY): a multicentre randomised controlled trial. Lancet. 2014;383(9919):796-806.

26. Braekken IH, Majida M, Engh ME, Bo K. Can pelvic floor muscle training reverse pelvic organ prolapse and reduce prolapse symptoms? An assessor-blinded, randomized, controlled trial. Am JObstet Gynecol. 2010;203(2):170.e1-e7.

27. Powers K, Lazarou G, Wang A, et al. Pessary use in advanced pelvic organ prolapse. Int Urogynecol J Pelvic Floor Dysfunct. 2006;17(2):160-164.

28. Wu V, Farrell SA, Baskett TF, Flowerdew G. A simplified protocol for pessary management. Obstet Gynecol. 1997;90(6):990-994.

29. Nygaard I, Bradley C, Brandt D; Women's Health Initiative. Pelvic organ prolapse in older women: prevalence and risk factors. Obstet Gynecol. 2004;104(3):489-497.

30. Swift SE, Tate SB, Nicholas J. Correlation of symptoms with degree of pelvic organ support in a general population of women: what is pelvic organ prolapse? Am J Obstet Gynecol. 2003;189(2):372-377.

31. Ulmsten U, Henriksson L, Johnson P, Varhos G. An ambulatory surgical procedure under local anesthesia for treatment of female urinary incontinence. Int Urogynecol J Pelvic Floor Dysfunct. 1996;7(2):81-85.

32. Fischer JE. Hernia repair: why do we continue to perform mesh repair in the face of the human toll of inguinodynia? Am J Surg. 2013;206(4): 619-623.

33. Scott NW, McCormack K, Graham P, Go PM, Ross SJ, Grant AM. Open mesh versus non-mesh for repair of femoral and inguinal hernia. Cochrane Database Syst Rev. 2002;(4):CD002197.

34. Bay-Nielsen M, Kehlet H, Strand L, et al. Quality assessment of 26,304 herniorrhaphies in Denmark: a prospective nationwide study. Lancet. 2001;358(9288):1124-1128.

35. Julian TM. The efficacy of Marlex mesh in the repair of severe, recurrent vaginal prolapse of the anterior midvaginal wall. Am J Obstet Gynecol. 1996;175(6):1472-1475.

36. Safir MH, Gousse AE, Rovner ES, Ginsberg DA, Raz S. 4-defect repair of grade 4 cystocele. J Urol. 1999;161(2):587-594.

37. Weber AM, Walters MD, Piedmonte MR, Ballard LA. Anterior colporrhaphy: a randomized trial of three surgical techniques. Am J Obstet Gynecol. 2001;185(6):1299-1304. 
38. Committee on Gynecologic Practice. Committee Opinion no. 513: vaginal placement of synthetic mesh for pelvic organ prolapse. Obstet Gynecol. 2011;118(6):1459-1464.

39. Jonsson Funk M, Edenfield AL, Pate V, Visco AG, Weidner AC, $\mathrm{Wu}$ JM. Trends in use of surgical mesh for pelvic organ prolapse. Am J Obstet Gynecol. 2013;208(1):79.e1-e7.

40. Albo ME, Richter HE, Brubaker L, et al. Burch colposuspension versus fascial sling to reduce urinary stress incontinence. $N$ Engl J Med. 2007;356(21):2143-2155.

41. Walter AJ, Hentz JG, Magrina JF, Cornella JL. Harvesting autologous fascia lata for pelvic reconstructive surgery: techniques and morbidity. Am J Obstet Gynecol. 2001;185(6):1354-1358.

42. Klinge U, Schumpelick V, Klosterhalfen B. Functional assessment and tissue response of short- and long-term absorbable surgical meshes. Biomaterials. 2001;22(11):1415-1424.

43. Barbolt TA. Biology of polypropylene/polyglactin 910 grafts. Int Urogynecol J Pelvic Floor Dysfunct. 2006;17 Suppl 1:S26-S30.

44. Chen CC, Ridgeway B, Paraiso MF. Biologic grafts and synthetic meshes in pelvic reconstructive surgery. Clin Obstet Gynecol. 2007; 50(2):383-411.

45. Falagas ME, Velakoulis S, Iavazzo C, Athanasiou S. Mesh-related infections after pelvic organ prolapse repair surgery. Eur J Obstet Gynecol Reprod Biol. 2007;134(2):147-156.

46. Ridgeway B, Chen CC, Paraiso MF. The use of synthetic mesh in pelvic reconstructive surgery. Clin Obstet Gynecol. 2008;51(1):136-152.

47. Amid PK. Classification of biomaterials and their related complications in abdominal wall hernia surgery. Hernia. 1997;1:15-21.

48. Hendrix SL, Clark A, Nygaard I, Aragaki A, Barnabei V, McTiernan A. Pelvic organ prolapse in the Women's Health Initiative: gravity and gravidity. Am J Obstet Gynecol. 2002;186(6):1160-1166.

49. Stanton SL, Hilton P, Norton C, Cardozo L. Clinical and urodynamic effects of anterior colporrhaphy and vaginal hysterectomy for prolapse with and without incontinence. Br J Obstet Gynaecol. 1982;89(6): 459-463.

50. Porges RF, Smilen SW. Long-term analysis of the surgical management of pelvic support defects. Am J Obstet Gynecol. 1994;171(6): $1518-1526$.

51. Chmielewski L, Walters MD, Weber AM, Barber MD. Reanalysis of a randomized trial of 3 techniques of anterior colporrhaphy using clinically relevant definitions of success. Am J Obstet Gynecol. 2011;205(1):69.e1-e8.

52. Nieminen K, Hiltunen R, Takala $T$, et al. Outcomes after anterior vaginal wall repair with mesh: a randomized, controlled trial with a 3 year follow-up. Am J Obstet Gynecol. 2010;203(3):235. e1-e8.

53. Altman D, Vayrynen T, Engh ME, Axelsen S, Falconer C; Nordic Transvaginal Mesh Group. Anterior colporrhaphy versus transvaginal mesh for pelvic-organ prolapse. $N$ Engl J Med. 2011;364(19): 1826-1836

54. Maher C, Feiner B, Baessler K, Schmid C. Surgical management of pelvic organ prolapse in women. Cochrane Database Syst Rev. 2013;4:CD004014.

55. Maher C. Anterior vaginal compartment surgery. Int Urogynecol J. 2013;24(11):1791-1802.

56. Allahdin S, Glazener C, Bain C. A randomised controlled trial evaluating the use of polyglactin mesh, polydioxanone and polyglactin sutures for pelvic organ prolapse surgery. J Obstet Gynaecol. 2008;28(4):427-431.

57. Sand PK, Koduri S, Lobel RW, et al. Prospective randomized trial of polyglactin 910 mesh to prevent recurrence of cystoceles and rectoceles. Am J Obstet Gynecol. 2001;184(7):1357-1362.

58. Rudnicki M, Laurikainen E, Pogosean R, Kinne I, Jakobsson U, Teleman P. Anterior colporrhaphy compared with collagen-coated transvaginal mesh for anterior vaginal wall prolapse: a randomised controlled trial. BJOG. 2014;121(1):102-110.

59. Cosson M, Collinet P, Occelli B, Narducci F, Crepin G. The vaginal patch plastron for vaginal cure of cystocele. Preliminary results for 47 patients. Eur J Obstet Gynecol Reprod Biol. 2001;95(1):73-80.
60. Gandhi S, Goldberg RP, Kwon C, et al. A prospective randomized trial using solvent dehydrated fascia lata for the prevention of recurrent anterior vaginal wall prolapse. Am J Obstet Gynecol. 2005;192(5): 1649-1654.

61. Handel LN, Frenkl TL, Kim YH. Results of cystocele repair: a comparison of traditional anterior colporrhaphy, polypropylene mesh and porcine dermis. J Urol. 2007;178(1):153-156.

62. Meschia M, Pifarotti P, Bernasconi F, Magatti F, Riva D, Kocjancic E. Porcine skin collagen implants to prevent anterior vaginal wall prolapse recurrence: a multicenter, randomized study. J Urol. 2007;177(1): 192-195.

63. Menefee SA, Dyer KY, Lukacz ES, Simsiman AJ, Luber KM, Nguyen JN. Colporrhaphy compared with mesh or graft-reinforced vaginal paravaginal repair for anterior vaginal wall prolapse: a randomized controlled trial. Obstet Gynecol. 2011;118(6):1337-1344.

64. Robert M, Girard I, Brennand E, et al. Absorbable mesh augmentation compared with no mesh for anterior prolapse: a randomized controlled trial. Obstet Gynecol. 2014;123(2 Pt 1):288-294.

65. Paraiso MF, Barber MD, Muir TW, Walters MD. Rectocele repair: a randomized trial of three surgical techniques including graft augmentation. Am J Obstet Gynecol. 2006;195(6):1762-1771.

66. Kuhn A, Gelman W, O'Sullivan S, Monga A. The feasibility, efficacy and functional outcome of local anaesthetic repair of anterior and posterior vaginal wall prolapse. Eur J Obstet Gynecol Reprod Biol. 2006; 124(1):88-92.

67. Abramov Y, Gandhi S, Goldberg RP, Botros SM, Kwon C, Sand PK. Site-specific rectocele repair compared with standard posterior colporrhaphy. Obstet Gynecol. 2005;105(2):314-318.

68. Maher CF, Qatawneh AM, Dwyer PL, Carey MP, Cornish A, Schluter PJ. Abdominal sacral colpopexy or vaginal sacrospinous colpopexy for vaginal vault prolapse: a prospective randomized study. Am J Obstet Gynecol. 2004;190(1):20-26.

69. Roovers JP, van der Vaart CH, van der Bom JG, van Leeuwen JH, Scholten PC, Heintz AP. A randomised controlled trial comparing abdominal and vaginal prolapse surgery: effects on urogenital function. BJOG. 2004;111(1):50-56.

70. Nygaard IE, McCreery R, Brubaker L, et al. Abdominal sacrocolpopexy: a comprehensive review. Obstet Gynecol. 2004;104(4):805-823.

71. Culligan PJ, Murphy M, Blackwell L, Hammons G, Graham C, Heit MH. Long-term success of abdominal sacral colpopexy using synthetic mesh. Am J Obstet Gynecol. 2002;187(6):1473-1480.

72. Karram M, Maher C. Surgery for posterior vaginal wall prolapse. Int Urogynecol J. 2013;24(11):1835-1841.

73. Tate SB, Blackwell L, Lorenz DJ, Steptoe MM, Culligan PJ. Randomized trial of fascia lata and polypropylene mesh for abdominal sacrocolpopexy: 5-year follow-up. Int Urogynecol J. 2011;22(2):137-143.

74. Culligan PJ, Blackwell L, Goldsmith LJ, Graham CA, Rogers A, Heit MH. A randomized controlled trial comparing fascia lata and synthetic mesh for sacral colpopexy. Obstet Gynecol. 2005;106(1): 29-37.

75. Claerhout F, De Ridder D, Van Beckevoort D, et al. Sacrocolpopexy using xenogenic acellular collagen in patients at increased risk for graft-related complications. Neurourol Urodyn. 2010;29(4): 563-567.

76. Quiroz LH, Gutman RE, Shippey S, et al. Abdominal sacrocolpopexy: anatomic outcomes and complications with Pelvicol, autologous and synthetic graft materials. Am J Obstet Gynecol. 2008;198(5):557. e1-e5.

77. Altman D, Anzen B, Brismar S, Lopez A, Zetterstrom J. Long-term outcome of abdominal sacrocolpopexy using xenograft compared with synthetic mesh. Urology. 2006;67(4):719-724.

78. Sokol AI, Iglesia CB, Kudish BI, et al. One-year objective and functional outcomes of a randomized clinical trial of vaginal mesh for prolapse. Am J Obstet Gynecol. 2012;206(1):86.e1-e9.

79. Maher CF, Feiner B, DeCuyper EM, Nichlos CJ, Hickey KV, O’Rourke P. Laparoscopic sacral colpopexy versus total vaginal mesh for vaginal vault prolapse: a randomized trial. Am J Obstet Gynecol. 2011; 204(4):360.e1-e7. 
80. Kapandji M. Cure des prolapsus uro-génitaux par la colpo-isthmocystopexie par bandelette transversale et la Douglassorraphie ligamento-péritonéale étagée et croisée. [Treatment of urogenital prolapse by colpo-isthmo-cystopexy with transverse strip and crossed, multiple layer, ligamento-peritoneal douglasorrhaphy]. Ann Chir. 1967;21(5):321-328. French.

81. Cornier E, Madelenat P. Hystéropéxie selon M. Kapandji: technique per-coelioscopique et résultats préliminaires. [The M Kapandji hysteropexy: a laparoscopic technic and preliminary results]. J Gynecol Obstet Biol Reprod (Paris). 1994;23(4):378-385. French.

82. Dubuisson JB, Yaron M, Wenger JM, Jacob S. Treatment of genital prolapse by laparoscopic lateral suspension using mesh: a series of 73 patients. J Minim Invasive Gynecol. 2008;15(1):49-55.

83. Dubuisson JB, Eperon I, Jacob S, et al. Réparation coelioscopique des prolapsus des organes pelviens par suspension prothétique latérale: une série continue de 218 patientes. [Laparoscopic repair of pelvic organ prolapse by lateral suspension with mesh: a continuous series of 218 patients]. Gynecol Obstet Fertil. 2011;39(3):127-131. French.

84. Dubuisson J, Eperon I, Dallenbach P, Dubuisson JB. Laparoscopic repair of vaginal vault prolapse by lateral suspension with mesh. Arch Gynecol Obstet. 2013;287(2):307-312.

85. Dallenbach P, Veit N. Robotically assisted laparoscopic repair of anterior vaginal wall and uterine prolapse by lateral suspension with mesh: initial experience and video. Int Urogynecol J. 2014;25(8):1137-1139.

86. Rogo-Gupta L, Rodriguez LV, Litwin MS, et al. Trends in surgical mesh use for pelvic organ prolapse from 2000 to 2010. Obstet Gynecol. 2012;120(5):1105-1115.

87. Margulies RU, Lewicky-Gaupp C, Fenner DE, McGuire EJ, Clemens JQ, Delancey JO. Complications requiring reoperation following vaginal mesh kit procedures for prolapse. Am J Obstet Gynecol. 2008;199(6): 678.e1-e4.

88. Abed H, Rahn DD, Lowenstein L, Balk EM, Clemons JL, Rogers RG; Systematic Review Group of the Society of Gynecologic Surgeons. Incidence and management of graft erosion, wound granulation, and dyspareunia following vaginal prolapse repair with graft materials: a systematic review. Int Urogynecol J. 2011;22(7):789-798.

89. Jia X, Glazener C, Mowatt G, et al. Systematic review of the efficacy and safety of using mesh in surgery for uterine or vaginal vault prolapse. Int Urogynecol J. 2010;21(11):1413-1431.
90. Diwadkar GB, Barber MD, Feiner B, Maher C, Jelovsek JE. Complication and reoperation rates after apical vaginal prolapse surgical repair: a systematic review. Obstet Gynecol. 2009;113(2 Pt 1):367-373.

91. Feiner B, Maher C. Vaginal mesh contraction: definition, clinical presentation, and management. Obstet Gynecol. 2010;115(2 Pt 1): 325-330.

92. Delavierre D, Rigaud J, Sibert L, Labat JJ. Définitions, classifications et lexique des douleurs pelvipérinéales chroniques. [Definitions, classifications and terminology of chronic pelvic and perineal pain]. Prog Urol. 2010;20(12):853-864. French.

93. Benson JT, Lucente V, McClellan E. Vaginal versus abdominal reconstructive surgery for the treatment of pelvic support defects: a prospective randomized study with long-term outcome evaluation. Am J Obstet Gynecol. 1996;175(6):1418-1421.

94. Lowman JK, Woodman PJ, Nosti PA, Bump RC, Terry CL, Hale DS Tobacco use is a risk factor for mesh erosion after abdominal sacra colpoperineopexy. Am J Obstet Gynecol. 2008;198(5):561.e1-e4.

95. Elneil S, Cutner AS, Remy M, Leather AT, Toozs-Hobson P, Wise B. Abdominal sacrocolpopexy for vault prolapse without burial of mesh: a case series. BJOG. 2005;112(4):486-489.

96. Cervigni M, Natale F. The use of synthetics in the treatment of pelvic organ prolapse. Curr Opin Urol. 2001;11(4):429-435.

97. Kaelin-Gambirasio I, Jacob S, Boulvain M, Dubuisson JB, Dallenbach P. Complications associated with transobturator sling procedures: analysis of 233 consecutive cases with a 27 months follow-up. BMC Womens Health. 2009;9:28

98. Barski D, Otto T, Gerullis H. Systematic review and classification of complications after anterior, posterior, apical, and total vaginal mesh implantation for prolapse repair. Surg Technol Int 2014;24:217-224.

99. Achtari C, Hiscock R, O’Reilly BA, Schierlitz L, Dwyer PL. Risk factors for mesh erosion after transvaginal surgery using polypropylene (Atrium) or composite polypropylene/polyglactin 910 (Vypro II) mesh. Int Urogynecol J Pelvic Floor Dysfunct. 2005;16(5):389-394.

100. Boennelycke M, Gras S, Lose G. Tissue engineering as a potential alternative or adjunct to surgical reconstruction in treating pelvic organ prolapse. Int Urogynecol J. 2013;24(5):741-747.
International Journal of Women's Health

\section{Publish your work in this journal}

The International Journal of Women's Health is an international, peerreviewed open-access journal publishing original research, reports, editorials, reviews and commentaries on all aspects of women's healthcare including gynecology, obstetrics, and breast cancer. The manuscript management system is completely online and includes

\section{Dovepress}

a very quick and fair peer-review system, which is all easy to use. Visit http://www.dovepress.com/testimonials.php to read real quotes from published authors. 